\title{
Nanoparticle Effects on Human Platelets in Vitro: A Comparison between PAMAM and Triazine Dendrimers
}

\author{
Alan E. Enciso ${ }^{1}$, Barry Neun ${ }^{2}$, Jamie Rodriguez ${ }^{2}$, Amalendu P. Ranjan ${ }^{3}$, \\ Marina A. Dobrovolskaia ${ }^{2, *}$ and Eric E. Simanek ${ }^{1, *}$ \\ 1 Department of Chemistry \& Biochemistry, Texas Christian University, Fort Worth, TX 76129, USA; \\ a.encisobarros@tcu.edu \\ 2 Nanotechnology Characterization Lab, Frederick National Laboratory for Cancer Research, Frederick, \\ MD 21702, USA; neunb@mail.nih.gov (B.N.); rodriguezjc@mail.nih.gov (J.R.) \\ 3 Department of Molecular and Medical Genetics \& Institute of Cancer Research, University of North Texas \\ Health Science Center, Fort Worth, TX 76109, USA; amalendu.ranjan@unthsc.edu \\ * Correspondence: marina@mail.nih.gov (M.A.D.); e.simanek@tcu.edu (E.E.S.); Tel.: +1-301-846-6939 (M.A.D.); \\ $+1-817-257-5355$ (E.E.S.)
}

Academic Editor: Ashok Kakkar

Received: 3 February 2016 ; Accepted: 21 March 2016 ; Published: 29 March 2016

\begin{abstract}
Triazine and PAMAM dendrimers of similar size and number of cationic surface groups were compared for their ability to promote platelet aggregation. Triazine dendrimers (G3, G5 and G7) varied in molecular weight from $8 \mathrm{kDa}-130 \mathrm{kDa}$ and in surface groups 16-256. PAMAM dendrimers selected for comparison included G3 (7 kDa, 32 surface groups) and G6 (58 kDa, 256 surface groups). The treatment of human platelet-rich plasma (PRP) with low generation triazine dendrimers $(0.01-1 \mu \mathrm{M})$ did not show any significant effect in human platelet aggregation in vitro; however, the treatment of PRP with larger generations promotes an effective aggregation. These results are in agreement with studies performed with PAMAM dendrimers, where large generations promote aggregation. Triazine dendrimers promote aggregation less aggressively than PAMAM dendrimers, a factor attributed to differences in cationic charge or the formation of supramolecular assemblies of dendrimers.
\end{abstract}

Keywords: dendrimer; triazine; PAMAM; platelet; biocompatibility

\section{Introduction}

Dendrimers are nanosized, hyperbranched polymers with low polydispersity that are amenable to synthetic manipulation [1-4]. While not yet realized, the potential for dendrimers to act as drug delivery vehicles has been long appreciated [5-9]. Our efforts, like others, rely on intravenous administration of such vehicles [10-13]. This strategy promotes interactions of these protein-sized architectures with endogenous proteins, cells, and aggregates such as lipoproteins. A common design strategy for the application of these materials relies on dendrimers to promote sustained systematic distribution by retention in the circulation. Accordingly, dendrimers will experience increased exposure time with components of the blood stream. Assessment of biocompatibility typically commences with studies of dendrimer interactions with specific components of the circulatory system. Interactions with platelets represent a common starting point for such studies. Platelets are abundant in the vasculature and are sensitive to changes in blood microenvironment [14]. Platelet aggregation is a critical step in the clotting cascade [15]. Agents that promote or attenuate this behavior are of clinical interest [16-21]. While nanomaterials have demonstrated these abilities, such effects are "off-target" if the goal is drug delivery [22]. 
Historically, PAMAM dendrimers have served as a benchmark for other classes of dendrimers. Here, we compare PAMAM standards with triazine dendrimers [23]. Earlier structure activity relationship studies with PAMAM dendrimers revealed that dendrimer size, zeta potential, and density of the surface amines are responsible for the dendrimer interaction with, and activation of, platelets $[14,22,23]$. The mechanism of activation has been attributed to the disturbance of the cellular membrane integrity [23]. However, the composition of triazine dendrimers is different to PAMAM dendrimers (Chart 1). The branching point for triazine dendrimers is the rigid, aromatic triazine ring. In contrast, PAMAM branch from a tertiary amine. Differences in flexibility, hydrophilicity, size, and basicity are apparent. For the studies described here, the triazine rings are interconnected with a tetraethyleneglycol group to promote water solubility. For simplicity, the molecules will be indicated by class and generation, abbreviated "G."

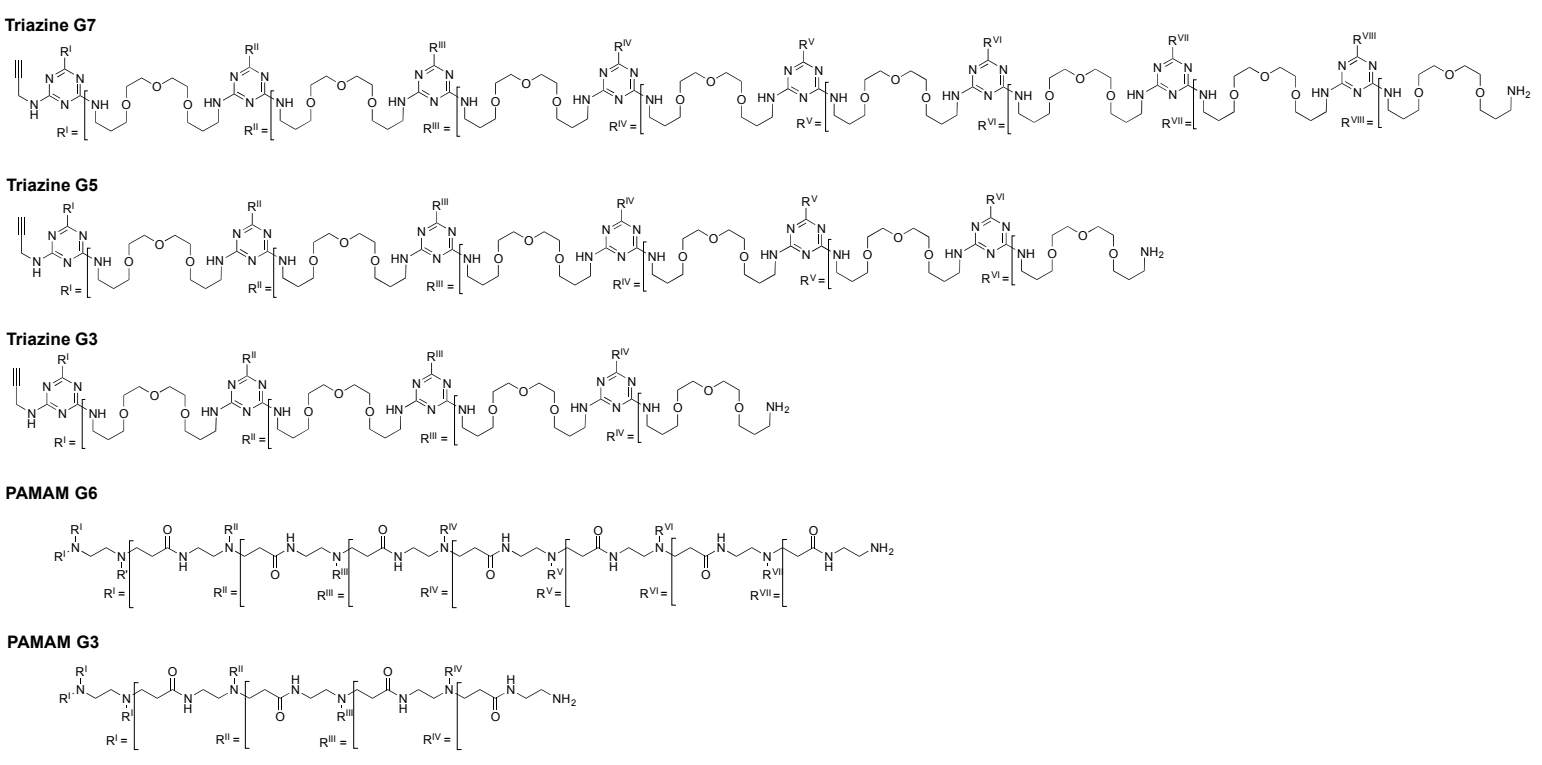

Chart 1. Structures of the triazine and PAMAM dendrimers examined.

\section{Results and Discussion}

\subsection{Zeta Potential}

Triazine and PAMAM dendrimers are intrinsically different in composition. However, at large generation both are perceived to exist as globular spheres resembling proteins with biophysical properties that is attributed to their surface chemistry [24-28]. The zeta-potentials measured for these molecules at near neutral $\mathrm{pH}$ using $10 \mathrm{mM}$ phosphate buffer (and $136 \mathrm{mM} \mathrm{NaCl}$ ) show that they are all cationic as expected, but the triazines bear less charge than the corresponding PAMAM, even when surface group numbers are identical. At $10 \mathrm{mM}$ buffer without added salt, the triazines zeta-potentials are $32 \mathrm{mV}, 22 \mathrm{mV}$, and $26 \mathrm{mV}$, respectively for G3, G5, and G7. This difference could be attributed to the preponderance of interior, tertiary amines of the PAMAM whose pKa are approximately 10 compared with the triazine sites with pKas of approximately 4.5.

Charge density might seem similar given similar charges and monomer size, but these dendrimers aggregate in solution. The triazines monomers of the dimensions shown in Table 1 are in equilibrium with multimeric aggregates measuring hundreds of nanometers. The data presented in Table 1 are summarized from our earlier studies [23,29,30]. Indeed, this behavior underscores the importance of these studies on triazines given their intended uses. While similar in branching architecture and surface chemistry, dendrimers within and across classes of composition can potentially display different behaviors in complex environments like the vasculature. 
Table 1. Comparison of triazine and PAMAM dendrimers.

\begin{tabular}{lccccc}
\hline Dendrimer & $\begin{array}{c}\text { Z-Potential } \\
(\mathbf{m} \mathbf{)})\end{array}$ & $\begin{array}{c}\text { Monomer } \\
\text { Size }(\mathbf{n m})\end{array}$ & $\begin{array}{c}\text { Peripheral } \\
\text { Amines }\end{array}$ & $\begin{array}{c}\text { Internal Tertiary } \\
\text { Amines }\end{array}$ & MW (Da) \\
\hline G3-Triazine & 23.1 & 3.7 & 16 & - & 7785 \\
G3-PAMAM & 43.3 & 3.1 & 32 & 30 & 6910 \\
G5-Triazine & 16.5 & 8.0 & 64 & - & $33 \mathrm{~K}$ \\
G6-PAMAM & 46.2 & 7.5 & 256 & 254 & $58 \mathrm{~K}$ \\
G7-Triazine & 19.8 & 13.7 & 256 & - & $130 \mathrm{~K}$ \\
\hline
\end{tabular}

\subsection{Platelet Aggregation}

Incubating triazine G3, G5, and G7 dendrimers in plate-rich plasma leads to platelet activation, which culminates in platelet aggregation. Using four different concentrations $(0.01 \mu \mathrm{M}, 0.10 \mu \mathrm{M}$, $1 \mu \mathrm{M}$, and $10 \mu \mathrm{M})$, we find that activation occurs in a dose-dependent and size-dependent manner. Triazine G5 and G7 dendrimers activate platelets more than triazine G3 dendrimers (Figure 1). Due to the insufficient quantity of material, the triazine G7 dendrimer was not assayed at the highest concentration. These results are in agreement with studies performed with PAMAM dendrimers that show increasing activation with increasing size [23].

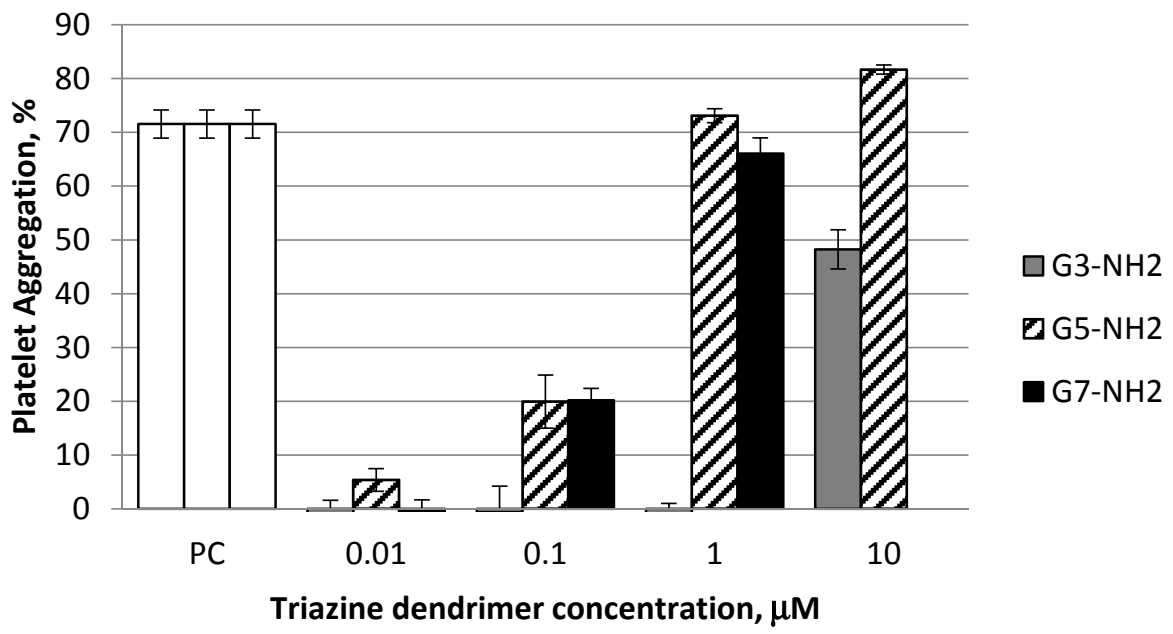

Figure 1. Induction of platelet aggregation by amine terminated triazine dendrimers is size-dependent. Different concentrations of generations 3,5 , and 7 of triazine dendrimers with amine terminal groups that were incubated with human platelet reach plasma for $15 \mathrm{~min}$ at $37^{\circ} \mathrm{C}$. After that, platelet count was performed using a Z2 cell and particle counter. Platelet count in the test samples was compared to that in the negative control sample to calculate percent platelet aggregation. Collagen was used as an assay positive control (PC). Shown is mean $\pm \mathrm{SD}(n=3)$.

In a comparative test, G3 and G7 triazine dendrimers $(1 \mu \mathrm{M})$ are seen to be less aggressive at platelet aggregation compared to their PAMAM counterparts of similar generation possessing similar physicochemical properties (G3 and G6) (Figure 2). Due to the absence of well characterized G7 PAMAM dendrimer, we used G6 PAMAM dendrimer in this study. Since platelet aggregation induction by PAMAM dendrimer increases with their size (23), it is reasonable to expect that platelet aggregation by G7 PAMAM dendrimer will be even stronger than that observed with G6. Therefore, the difference between G7 of Triazine and G7 PAMAM dendrimers would be even greater than that reported in this study. 


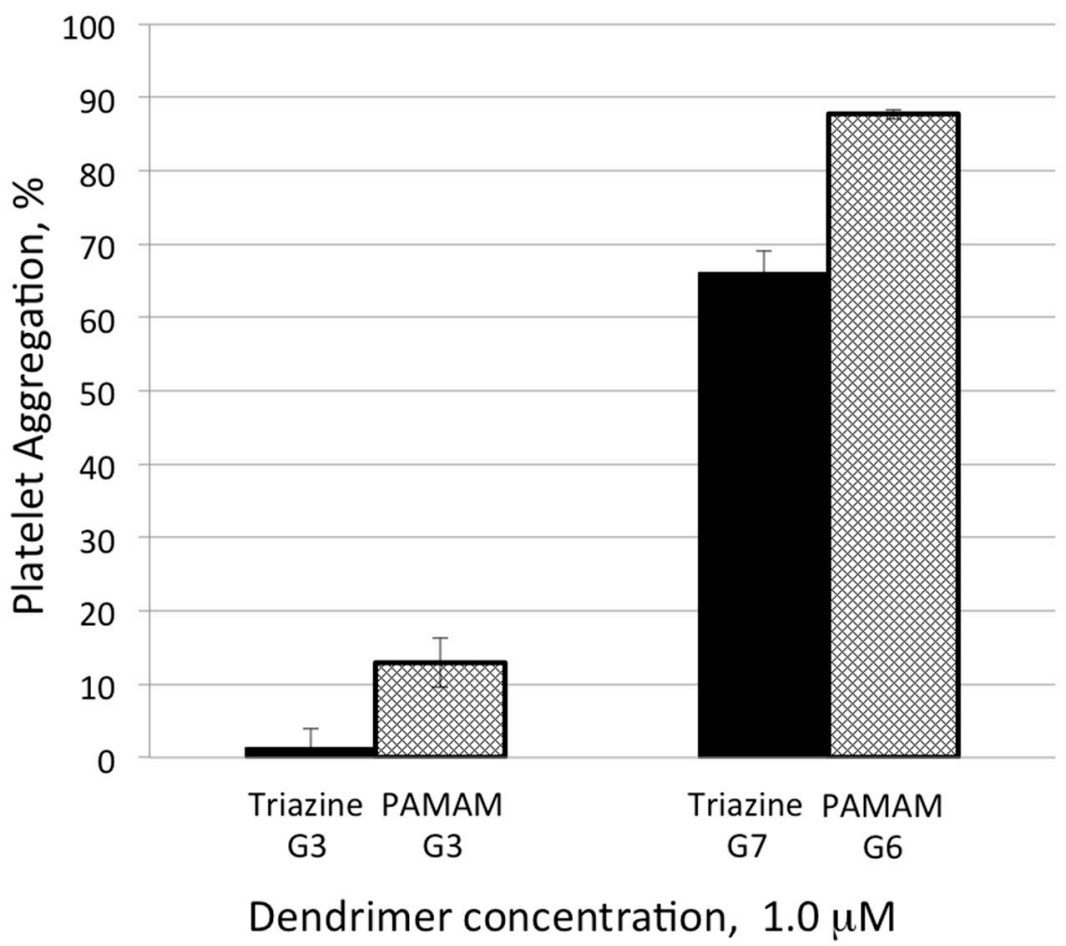

Figure 2. Cationic triazine dendrimers are less reactive with human platelets than cationic PAMAM dendrimers of similar size. G3- and G7-amine-terminated triazine dendrimers and G3- and G6-amine terminated PAMAM dendrimers at equivalent molar concentrations were incubated with human platelet reach plasma for $15 \mathrm{~min}$ at $37^{\circ} \mathrm{C}$. After that, platelet count was performed using a Z2 cell and particle counter equipped with a 5- $\mu \mathrm{m}$ aperture tube. Platelet count in the test samples was compared to that in the negative control sample to calculate percent platelet aggregation. Collagen was used as an assay positive control (data not shown). Shown is mean $\pm \mathrm{SD}(n=3)$.

\section{Materials and Methods}

\subsection{Reagents}

DPBS $\left(\mathrm{Ca}^{2+} / \mathrm{Mg}^{2+}\right.$ free), poly-L-lysine hydrobromide, polymyxin B, 2MeSAMP, and 1,10-phenantroline were from Sigma-Aldrich (St. Louis, MO, USA). G3 and G6 PAMAM dendrimers with amine surface were from Dendritic Nanotechnologies Inc. (Mount Pleasant, MI, USA). Collagen was purchased from Helena Laboratories (Beaumont, TX, USA). Triazine dendrimers were synthesized according to procedures previously reported [31,32].

\subsection{Research Donor Blood}

Healthy volunteer blood specimens were drawn under NCI-Frederick Protocol OH99-C-N046. Blood was collected in BD vacutainer tubes containing sodium citrate as an anticoagulant. To avoid individual variability, specimens from at least three donors were pooled.

\subsection{Platelet Aggregation}

To study particles effects on platelet aggregation, whole blood was centrifuged $8 \mathrm{~min}$ at $200 \times g$ in order to obtain platelet rich plasma (PRP). PRP was treated with nanoparticles, PBS (negative control), or collagen (positive control) for $15 \mathrm{~min}$ at $37^{\circ} \mathrm{C}$. After that, single platelet count was conducted using a Z2 counter and a size analyzer (Beckman Coulter, Brea, CA, USA). Difference in single platelet count between negative control and test samples was used to calculate percent platelet aggregation. Additional control included incubation of platelet poor plasma and PBS with particles and analyzing these samples on the instrument. These controls were used to monitor potential particle aggregation 
in the presence of plasma proteins to avoid false-negative results. Detailed protocol is available [33]. To study potential particle contamination with endotoxin, the test samples were analyzed by turbidity LAL assay according to the protocol published [34]. Endotoxin was not detected in any test samples at concentrations used in the platelet aggregation assay.

\subsection{Zeta Potential Measurements}

The zeta potential measurement of all the generations of dendrimers were conducted with Zetasizer Nano-ZS (Malvern Instruments, Westborough, MA, USA). Samples were suspended in $1 \times$ PBS pH 7.4 (with and without salt) and placed in disposable folded capillary cells DTS1070 (Malvern Instruments, Westborough, MA, USA). The electrophoretic mobility of the samples were measured in an applied electric field. Twelve zeta potential measurements were collected for each run, and the results were averaged. The Zeta potential value was calculated directly from the Smoluchowski model using the Malvern software.

\section{Conclusions}

Consistent with Tomalia's nanoperiodicity hypothesis [35-37], both triazine and PAMAM dendrimers activate platelets in a size- and charge-dependent manner in that dendrimers of earlier generations (G3) exhibit lower potency in activating platelets than their higher generation (G6 and G7) counterparts. Dendrimers of earlier generation are smaller in hydrodynamic size and have lower number of surface amines. The data obtained for PAMAM dendrimers in our study is similar to the earlier reports [22,23]. Of interest, herein we demonstrated that Triazine dendrimers are less potent than their PAMAM counterparts. The diminished activity displayed by the triazine dendrimers is likely attributed to the lessor density of surface amines. That is, triazine dendrimers due to the lack of interior groups protonated near neutral $\mathrm{pH}$. Systemic administration of cationic PAMAM dendrimers results in consumptive coagulopathy, a thrombogenic disorder halting the use of these particles as drug delivery vehicles [22]. The data presented in our study highlight less thrombogenic properties of cationic triazine dendrimers and warrant further investigation of these particles as potential drug carriers.

Acknowledgments: We thank the Robert A. Welch Foundation (P-0008) and DOD (W81XWH-12-1-0338). The study was supported in part by federal funds from the National Cancer Institute, National Institutes of Health, under contract HHSN261200800001E (M.D., B.N. and J.R.). The content of this publication does not necessarily reflect the views or policies of the Department of Health and Human Services, nor does mention of trade names, commercial products, or organizations imply endorsement by the U.S. Government.

Author Contributions: M.A.D. conceived the biological experiments and led the team comprised of B.N. and J.R. B.N. and J.R. performed endotoxin and platelet aggregation studies, respectively. E.E.S. conceived the synthesis and physicochemical characterization experiments and led the team comprised of A.E.E. and A.P.R. A.E. prepared the samples. A.P.R. performed DLS and Z-potential analysis. All parties contributed to the preparation of the manuscript.

Conflicts of Interest: The authors declare no conflict of interest.

\section{References}

1. Sowinska, M.; Urbanczyk-Lipkowska, Z. Advances in the chemistry of dendrimers. New J. Chem. 2014, 38, 2168-2203. [CrossRef]

2. Deng, X.-X.; Du, F.-S.; Li, Z.-C. Combination of orthogonal ABB and ABC multicomponent reactions toward efficient divergent synthesis of dendrimers with structural diversity. ACS Macro Lett. 2014, 3, 667-670. [CrossRef]

3. Patra, S.; Kozura, B.; Huang, A.Y.-T.; Enciso, A.E.; Sun, X.; Hsieh, J.-T.; Kao, C.-L.; Chen, H.-T.; Simanek, E.E. Dendrimers terminated with dichlorotriazine groups provide a rout to compositional diversity. Org. Lett. 2013, 15, 3808-3811. [CrossRef] [PubMed]

4. Simanek, E.E.; Abdou, H.; Lalwani, S.; Lim, J.; Mintzer, M.; Venditto, V.J.; Vittur, B. The 8 year thicket of triazine dendrimers: Strategies, targets and applications. Proc. R. Soc. A 2010, 466, 1445-1468. [CrossRef] 
5. Liu, Y.; Ng, Y.; Toh, M.R.; Chiu, G.N.C. Lipid-dendrimer hybrid nanosystem as a novel delivery system for paclitaxel to treat ovarian cancer. J. Control. Release 2015, 220, 438-446. [CrossRef] [PubMed]

6. Yu, M.; Jie, X.; Chen, C.; Shen, W.; Cao, Y.; Lian, G.; Qi, R. Recent advances in dendrimer research for cardiovascular diseases. Biomacromolecules 2015, 16, 2588-2598. [CrossRef] [PubMed]

7. Witte, A.B.; Timmer, C.M.; Gam, J.J.; Choi, S.K.; Banaszak, M.M.; Orr, B.G.; Baker, J.R., Jr.; Sinniah, K. Biophysical characterization of a riboflavin-conjugated dendrimer platform for targeted drug delivery. Biomacromolecules 2012, 13, 507-516. [CrossRef] [PubMed]

8. Yuan, H.; Luo, K.; Lai, Y.; Pu, Y.; He, B.; Wang, G.; Wu, Y.; Gu, Z. A novel poly(L-glutamic acid) dendrimer based drug delivery system with both $\mathrm{pH}$-sensitive and targeting functions. Mol. Pharm. 2010, 7, 953-962. [CrossRef] [PubMed]

9. Desai, P.N.; Yuan, Q.; Yang, H. Synthesis and characterization of photocurable polyamidoamine dendrimer hydrogels as a versatile platform for tissue engineering and drug delivery. Biomacromolecules 2010, 11, 666-673. [CrossRef] [PubMed]

10. Lim, J.; Simanek, E.E. Triazine dendrimers as drug delivery systems: From synthesis to therapy. Adv. Drug Deliv. Rev. 2012, 64, 826-835. [CrossRef] [PubMed]

11. Lim, J.; Lo, S.-T.; Hill, S.; Pavan, G.M.; Sun, X.; Simanek, E.E. Antitumor activity and molecular dynamics simulations of paclitaxel-laden triazine dendrimers. Mol. Pharm. 2012, 9, 404-412. [CrossRef] [PubMed]

12. Simanek, E.E.; Enciso, A.E.; Pavan, G.M. Computational design principles for the Discovery of bioactive dendrimers: [s]-triazines and other examples. Exp. Opin. Drug Disc. 2013, 9, 1057-1069. [CrossRef] [PubMed]

13. Lee, C.; Lo, S.-T.; Lim, J.; da Costa, V.C.; Ramezani, S.; Öz, O.K.; Pavan, G.M.; Annunziata, O.; Sun, X.; Simanek, E.E. Design, synthesis and biological assessment of a triazine dendrimer with approximately 16 paclitaxel groups and 8 PEG groups. Mol. Pharm. 2013, 10, 4452-4461. [CrossRef] [PubMed]

14. Jones, C.F.; Campbell, R.A.; Franks, Z.; Gibson, C.C.; Thiagarajan, G.; Vieira-de-Abreu, A.; Sukavaneshvar, S.; Mohammad, S.F.; Li, D.Y.; Ghandehari, H.; et al. Cationic PAMAM dendrimers disrupt key platelet functions. Mol. Pharm. 2012, 9, 1599-1611. [CrossRef] [PubMed]

15. Simak, J. Nanotoxicity in Blood: Effects of Engineered Nanomaterials on Platelets. In Nanotoxicity: From in Vivo and in Vitro Models to Health Risks, 1st ed.; Sahu, S.C., Casciano, D.A., Eds.; John Wiley and Sons Ltd.: Chichester, UK, 2009; pp. 191-225.

16. Dong, H.-P.; Wu, H.-M.; Chen, S.-J.; Chen, C.-Y. The effect of butanolides from Cinnamomum tenuifolium on platelet aggregation. Molecules 2013, 18, 11836-11841. [CrossRef] [PubMed]

17. Cejas, M.A.; Chen, C.; Kinney, W.A.; Maryanoff, B.E. Nanoparticles that display short collagen-related peptides. Potent stimulation of human platelet aggregation by triple helical motifs. Bioconjugate Chem. 2007, 18, 1025-1027. [CrossRef] [PubMed]

18. Okamura, Y.; Handa, M.; Suzuki, H.; Ikeda, Y.; Takeoka, S. New strategy of platelet substitutes for enhancing platelet aggregation at high shear rates: Cooperative effects of a mixed system of fibrinogen gamma-chain dodecapeptide- or glycoprotein Ibalpha-conjugated latex beads under flow conditions. J. Artif. Organs 2006, 9, 251-258. [CrossRef] [PubMed]

19. Zhu, J.; Xue, J.; Guo, Z.; Zhang, L.; Marchant, R.E. Biomimetic glycoliposomes as nanocarriers for targeting P-selectin on activated platelets. Bioconjugate Chem. 2007, 18, 1366-1369. [CrossRef] [PubMed]

20. Fernandes, E.G.; de Queiroz, A.A.; Abraham, G.A.; San Roman, J. Antithrombogenic properties of bioconjugate streptokinase-polyglycerol dendrimers. J. Mater. Sci. Mater. Med. 2006, 17, 105-111. [CrossRef] [PubMed]

21. Kim, Y.; Klutz, A.M.; Hechler, B.; Gao, Z.G.; Gachet, C.; Jacobson, K.A. Application of the functionalized congener approach to dendrimer-based signaling agents acting through $\mathrm{A}(2 \mathrm{~A})$ adenosine receptors. Purinergic Signal. 2009, 5, 39-50. [CrossRef] [PubMed]

22. Jones, C.F.; Campbell, R.A.; Brooks, A.E.; Assemi, S.; Tadjiki, S.; Thiagarajan, G.; Mulcock, C.; Weyrich, A.S.; Brooks, B.D.; Ghandehari, H.; et al. Cationic PAMAM dendrimers aggressively initiate blood clot formation. ACS Nano 2012, 6, 9900-9910. [CrossRef] [PubMed]

23. Dobrovolskaia, M.A.; Patri, A.K.; Simak, J.; Hall, J.B.; Semberova, J.; de Paoli Lacerda, S.H.; McNeil, S.E. Nanoparticle size and surface charge determine effects of PAMAM dendrimers on human platelets in vitro. Mol. Pharm. 2012, 9, 382-393. [CrossRef] [PubMed]

24. Esfand, R.; Tomalia, D.A. Poly(amidoamine) (PAMAM) dendrimers: From biomimicry to drug delivery and biomedical applications. Drug Discov. Today 2001, 6, 427-436. 
25. Svenson, S.; Tomalia, D.A. Dendrimers in biomedical applications-Reflections on the field. Adv. Drug Deliv. Rev. 2005, 57, 2106-2129. [CrossRef] [PubMed]

26. Tomalia, D.A.; Reyna, L.A.; Svenson, S. Dendrimers as multi-purpose nanodevices for oncology drug delivery and diagnostic imaging. Biochem. Soc. Trans. 2007, 35, 61-67. [CrossRef] [PubMed]

27. Menjoge, A.R.; Kannan, R.M.; Tomalia, D.A. Dendrimer-based drug and imaging conjugates: Design considerations for nanomedical applications. Drug Discov. Today 2010, 15, 171-185. [CrossRef] [PubMed]

28. Kannan, R.M.; Nance, E.; Kannan, S.; Tomalia, D.A. Emerging concepts in dendrimer-based nanomedicine: From design principles to clinical applications. J. Intern. Med. 2014, 276, 579-617. [CrossRef] [PubMed]

29. Dobrovolskaia, M.A.; Patri, A.K.; Potter, T.M.; Rodriguez, J.C.; Hall, J.B.; McNeil, S.E. Dendrimer-induced leukocyte procoagulant activity depends on particle size and surface charge. Nanomedicine 2012, 7, 245-256. [CrossRef] [PubMed]

30. Lo, S.T.; Stern, S.; Clogston, J.D.; Zheng, J.; Adiseshaiah, P.P.; Dobrovolskaia, M.; Lim, J.; Patri, A.K.; Sun, X.; Simanek, E.E. Biological assessment of triazine dendrimer:toxicological profiles, solution behavior, biodistribution, drug release andefficacy in a PEGylated, paclitaxel construct. Mol. Pharm. 2010, 7, 993-1006. [CrossRef] [PubMed]

31. Enciso, A.E.; Abid, Z.M.; Simanek, E.E. Rapid, semi-automated convergent synthesis of low generation triazine dendrimers using microwave assisted reactions. Polym. Chem. 2014, 5, 4635-4640. [CrossRef]

32. Lim, J.; Kostiainen, M.; Maly, J.; da Costa, V.C.; Annunziata, O.; Pavan, G.M.; Simanek, E.E. Synthesis of Large Dendrimers with the Dimensions of Small Viruses. J. Am. Chem. Soc. 2013, 135, 4660-4663. [CrossRef] [PubMed]

33. Assay Cascade Protocols, Frederick National Lab, Nanotechnology Characterization Laboratory. Available online: http://ncl.cancer.gov/NCL_Method_ITA-2.pdf (accessed on 28 March 2016).

34. Assay Cascade Protocols, Frederick National Lab, Nanotechnology Characterization Laboratory. Available online: http:/ /ncl.cancer.gov/NCL_Method_STE-1.2.pdf (accessed on 28 March 2016).

35. Tomalia, D.A. Dendritic effects: Dependecy of dendritic nano-periodic property patterns on critical nanoscale design parameters (CNDPs). New J. Chem. 2012, 36, 264-281. [CrossRef]

36. Tomalia, D.A. In quest of a systematic framework for unifying and defining nanoscience. J. Nanopart. Res. 2009, 11, 1251-1310. [CrossRef] [PubMed]

37. Tomalia, D.A.; Khanna, S.N. A systematic framework and nanoperiodic concept for unifying nanoscience: Hard/Soft nanoelements, superatoms, meta-atoms, new emerging properties, periodic property patterns, and predictive mendeleev-like nanoperiodic tables. Chem. Rev. 2016, 116, 2705-2774. [CrossRef] [PubMed]

Sample Availability: Samples of the compounds G1-G9 triazine dendrimers are available from the authors.

(C) 2016 by the authors; licensee MDPI, Basel, Switzerland. This article is an open access article distributed under the terms and conditions of the Creative Commons by Attribution (CC-BY) license (http://creativecommons.org/licenses/by/4.0/). 